\title{
Effects of sodium metabisulphite on guinea pig contractile airway smooth muscle responses in vitro
}

\author{
J Sun, T Sakamoto, K F Chung
}

\begin{abstract}
Background - Sodium metabisulphite (MBS) is known to induce bronchoconstriction in asthmatic patients. The effects of MBS on guinea pig airway smooth muscle and on neurally mediated contraction in vitro have been examined. Methods - Tracheal and bronchial airway segments were placed in oxygenated buffer solution and electrical field stimulation was performed in the presence of indomethacin $\left(10^{-5} \mathrm{M}\right)$ and propranolol $\left(10^{-6}\right.$ $M)$ for the measurement of isometric tension. Atropine $\left(10^{-6} \mathrm{M}\right)$ was added to bronchial tissues.

Results - Concentrations of MBS up to $10^{-3}$ $M$ had no direct effect on airway smooth muscle contraction and did not alter either tracheal smooth muscle contraction induced by electrical field stimulation at all frequencies or acetylcholine-induced tracheal smooth muscle contraction. There was a similar response in the absence of epithelium, except for potentiation of the response induced by electrical field stimulation at $0.5 \mathrm{~Hz}(24 \quad(10) \%$ increase $)$. However, MBS $\left(10^{-5}, 10^{-6}\right.$ and $\left.10^{-7} \mathrm{M}\right)$ augmented neurally-mediated non-adrenergic non-cholinergic contractile responses in the bronchi $(13.3(3.2) \%, 23.8$ $(9 \cdot 6) \%$, and $6 \cdot 4(1 \cdot 6) \%$, respectively). MBS had no effect on the contractile response induced by substance $P$, but at higher concentrations $\left(10^{-3} M\right.$ and $\left.10^{-4} M\right)$ it caused a time-dependent attenuation of responses induced by either electrical field stimulation or exogenously applied acetylcholine or substance $\mathbf{P}$.

Conclusions - MBS had no direct contractile responses but enhanced bronchoconstriction induced by activation of non-cholinergic neural pathways in the bronchus, probably through increased release of neuropeptides. At high concentrations MBS inhibited contractile responses initiated by receptor or neural stimulation.

(Thorax 1995;50:875-879)
\end{abstract}

Keywords: sodium metabisulphite, cholinergic nerves, non-adrenergic non-cholinergic, sulphur dioxide, airway smooth muscle.

Sodium metabisulphite (MBS) is widely used as a food preservative and can induce bronchoconstriction in patients with asthma but not in normal individuals. ${ }^{1-4} \mathrm{MBS}$-induced bronchoconstriction is mediated through cholin- ergic pathways to a small extent, ${ }^{23}$ and it is possible that the non-cholinergic component of this response involves the release of tachykinins. Studies in the anaesthetised guinea pig have shown that, while a cholinergic reflex is partly involved in MBS-induced bronchoconstriction, ${ }^{4}$ tachykinins acting partially through both neurokinin $\mathrm{NK}_{1}$ and $\mathrm{NK}_{2}$ receptors may also be released. ${ }^{5}$ In addition, MBS induces plasma extravasation in the airways of guinea pigs, an effect which is also partly mediated through tachykinin release. ${ }^{6}$ It is not known, however, whether MBS could have direct or indirect effects on airway smooth muscle responses.

In the present study we have examined the responses of the guinea pig airway smooth muscle to MBS added directly to airway preparations in vitro under isometric conditions. In addition, we determined whether MBS could modulate airway smooth muscle responses induced by the release of acetylcholine and tachykinins from airway nerves. Because guinea pig tracheal preparations demonstrate a predominantly cholinergic response and bronchial preparations both cholinergic and non-cholinergic components following electrical field stimulation, ${ }^{7}$ we examined the effects of MBS on the contractile responses of both tracheal and bronchial preparations to electrical field stimulation.

\section{Methods}

TISSUE PREPARATION

Male Dunkin-Hartley guinea pigs weighing $350-500 \mathrm{~g}$ were sacrificed by cervical dislocation. The airways (from larynx to whole lung) were rapidly removed and placed in oxygenated modified Krebs-Henseleit solution of the following composition (mM): $\mathrm{NaCl} 118$, $\mathrm{KCl} 5 \cdot 9, \mathrm{MgSO}_{4} 1 \cdot 2, \mathrm{CaCl}_{2} 2 \cdot 5, \mathrm{NaHCO}_{3}$ $25 \cdot 5$, and glucose $5 \cdot 05$. After careful dissection of connective tissue and lung parenchyma from the airway (from larynx to second generation bronchi), the trachea was opened longitudinally by cutting through the cartilage in its anterior aspect (opposite the smooth muscle layer) and then cut transversely with each segment containing 3-4 cartilaginous rings. In some experiments removal of the airway epithelial layer was achieved by gently rubbing the luminal surface to the trachea with a cotton wool applicator, which consistently achieves epithelial denudation as assessed by light microscopy. ${ }^{7}$ For the bronchial preparations bronchi were separated into main and hilar sections respectively. 
Tracheal and bronchial strips were suspended between platinum plate electrodes approximately $15 \mathrm{~cm}$ apart in $15 \mathrm{ml}$ organ baths containing Krebs solution bubbled continuously with a mixture of $95 \% \mathrm{O}_{2}$ and $5 \%$ $\mathrm{CO}_{2}$ at $37^{\circ} \mathrm{C}$ with $\mathrm{pH}$ at $7 \cdot 4$. Indomethacin $\left(10^{-5} \mathrm{M}\right)$ and propranolol $\left(10^{-6} \mathrm{M}\right)$ were present throughout the experiments, and atropine $\left(10^{-6} \mathrm{M}\right)$ was added for studies involving bronchial strips only. Atropine was not added to tracheal strips because it completely abolishes responses to electrical field stimulation. ${ }^{7}$ The segments were left to equilibrate for at least one hour with frequent washing and the resting tensions were adjusted to $1.5 \mathrm{~g}$ for the trachea and $0.5 \mathrm{~g}$ for the bronchi. These resting tensions were previously found to be optimal for measuring changes in isometric tensions. Isometric contractile responses were measured with Grass FT.03 force displacement transducers and recorded on a Graphic Linearcorder (Mark VII) polygraph (Graphtec Ltd, Nantwich, Cheshire, UK).

\section{ELECTRICAL FIELD STIMULATION}

Biphasic square wave pulses were delivered for 20 second periods from an electrical stimulator with a voltage of $20 \mathrm{~V}$ at source and pulse duration of $0.5 \mathrm{~m}$. Tracheal strips were first stimulated with the maximum frequency of $50 \mathrm{~Hz}$ four successive times, at intervals of three minutes each. A control frequency-response curve of the strips was performed after the resting tension had returned to a stable baseline. For each frequency-response curve, pulses of increasing frequency (from 0.5 to $50 \mathrm{~Hz}$ ) were delivered every three minutes. Two successive reproducible control frequency-response curves were obtained before MBS or

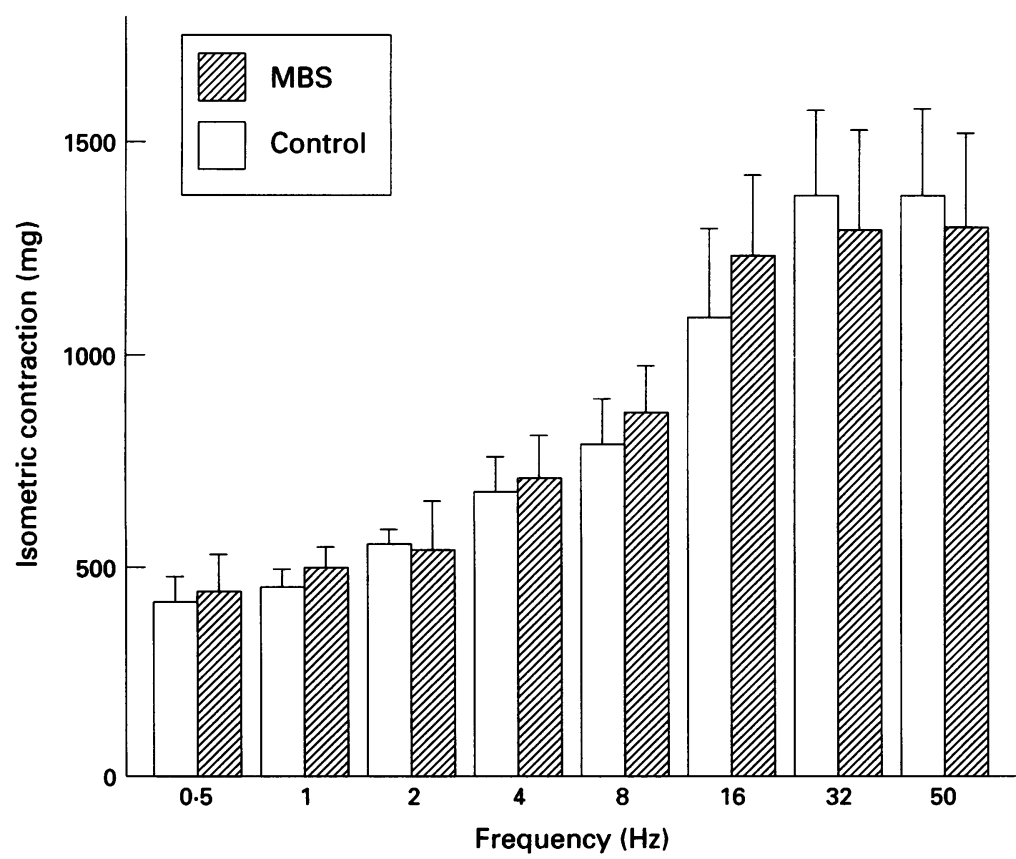

Figure 1 Effect of sodium metabisulphite (MBS $\left.10^{-6} \mathrm{M}\right)$ or control on contractile responses of guinea pig tracheal smooth muscle strips induced by increasing frequencies of electrical field stimulation $(0.5-50 \mathrm{~Hz}, 20 \mathrm{~V}, 0.5 \mathrm{~ms}, 20 \mathrm{~s})$ in the presence of propranolol $\left(10^{-6} \mathrm{M}\right)$ and indomethacin $\left(10^{-5} \mathrm{M}\right)$. The epithelium has been left intact. Data are shown as mean (SE) of 5-6 guinea pigs. diluent was added to the bath. After incubating for 20 minutes, electrical field stimulation was repeated in the same tissue with increasing frequencies of stimulation.

For bronchial strips, stimuli at a frequency of $8 \mathrm{~Hz}$ were delivered every 30 minutes after the resting tension of the smooth muscle had returned to its baseline. A frequency-response curve of the bronchial preparation was not possible to perform because repeated stimulations at different frequencies gave inconsistent responses. However, repeated stimulations at a single frequency were reproducible and at least two successive reproducible control responses to $8 \mathrm{~Hz}$ were obtained before MBS or diluent was added to the bath. Electrical field stimulation was repeated after incubation for 20 minutes with the drugs. Only one concentration of MBS was tested for each tracheal or bronchial preparation $\left(10^{-7}-10^{-3} \mathrm{M}\right)$.

ACETYLCHOLINE AND SUBSTANCE P RESPONSES The effects of MBS $\left(10^{-3} \mathrm{M}\right.$ and $\left.10^{-6} \mathrm{M}\right)$ on cumulative concentration responses to acetylcholine $\left(10^{-8}-10^{-3} \mathrm{M}\right)$ were studied in tracheal strips, and to substance $P\left(10^{-8}-10^{-5} \mathrm{M}\right)$ were studied in both tracheal (with epithelium intact or removed) and bronchial strips. The results were expressed as a percentage of the maximum contraction induced by the agonists themselves, but for substance $P$ the results were expressed as a percentage of the maximum contraction induced by carbachol $\left(10^{-3} \mathrm{M}\right)$.

\section{DRUGS AND SOLUTIONS}

Drugs and chemicals were obtained from the following sources: atropine sulphate (Phoenix Pharmaceuticals Ltd, Gloucester, UK); propranolol hydrochloride (Zeneca plc, Macclesfield, UK); substance $P$, acetylcholine chloride, indomethacin, and MBS (Sigma Chemical Co, Poole, UK). Stock solutions of MBS were made up in distilled water 24 hours

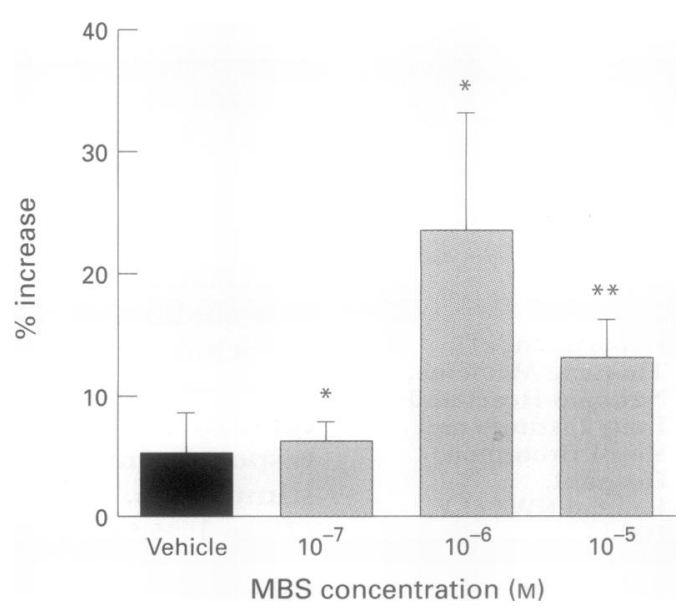

Figure 2 Enhancing effect of sodium metabisulphite (MBS $\left.10^{-7}-10^{-5} \mathrm{M}\right)$ expressed as percentage increase above control responses on non-adrenergic, non-cholinergic contraction of guinea pig bronchial smooth muscle strips induced by electrical field stimulation at $8 \mathrm{~Hz}(20 \mathrm{~V}$, $0.5 \mathrm{~ms}, 20 \mathrm{~s})$ in the presence of propranolol $\left(10^{-6} \mathrm{M}\right)$, atropine $\left(10^{-6} \mathrm{M}\right)$, and indomethacin $\left(10^{-5} \mathrm{M}\right)$. Data atropine $\left(10^{-6} M\right)$, and indomethacin $\left(10^{-5} M\right)$. Data
are shown as mean $(S E)$ of $6-8$ guinea pigs. ${ }^{*} p<0.05$; ${ }_{* *} p<0.01$ compared with vehicle-treated tissues. 


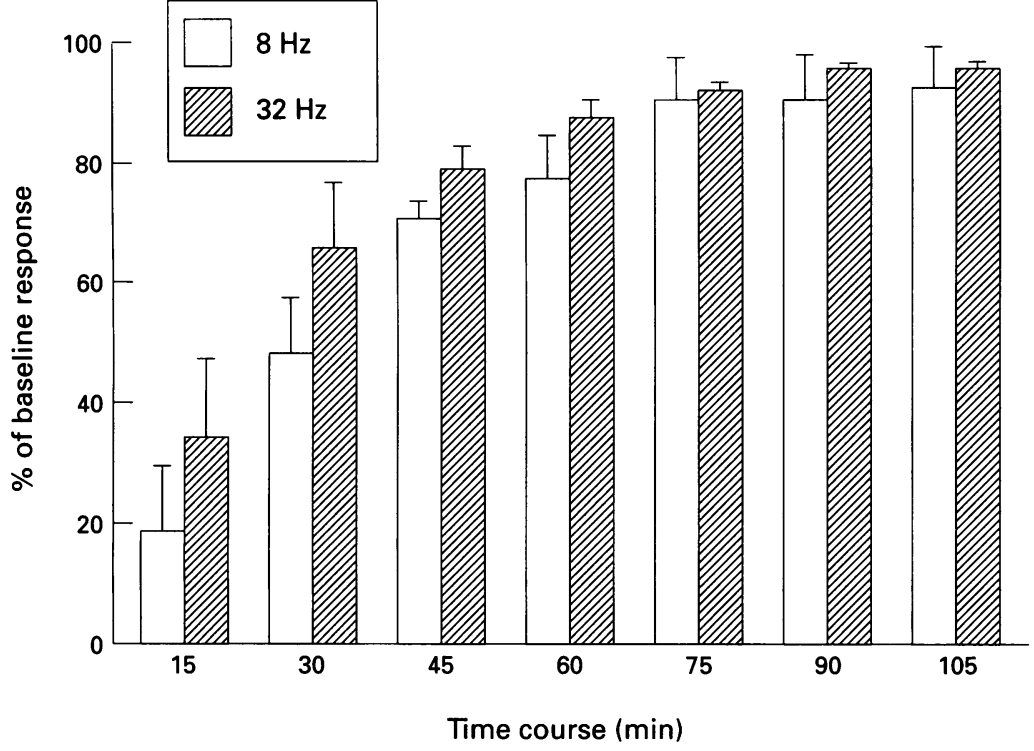

Figure 3 Time course of the inhibitory effect of sodium metabisulphite $\left(M B S 10^{-3} \mathrm{M}\right)$ on the contraction of guinea pig tracheal strips induced by electrical field stimulation at 8 and $32 \mathrm{~Hz}$. The epithelium has been left intact. Data are shown as mean (SE) of 4-5 guinea pigs and expressed as percentage response in the absence of MBS.

before the experiment and then further diluted also in distilled water to the appropriate concentration on the experimental day. Fresh solutions of drugs were made up daily. The control solutions for MBS were made by adjusting the $\mathrm{pH}$ of distilled water to the same $\mathrm{pH}$ as MBS solution $\left(10^{-3} \mathrm{M} ; \mathrm{pH} 3.75\right)$ using sulphuric acid.
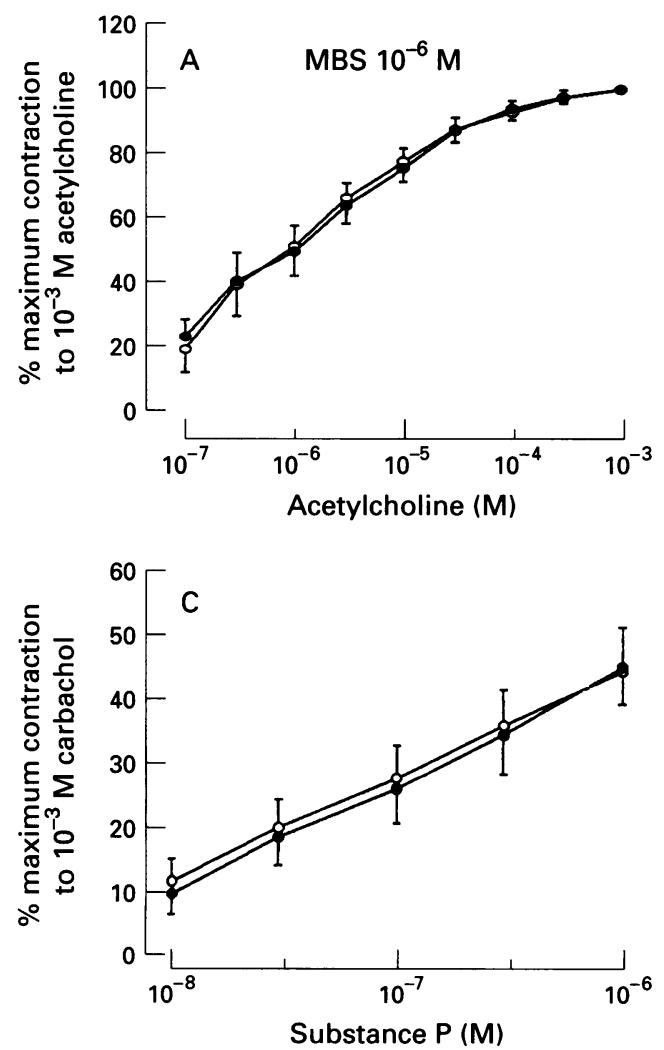

\section{DATA ANALYSIS}

Results are expressed as mean (SE). Electrical field stimulation frequency-response curves were first obtained in the absence of MBS and then repeated in the presence of one single concentration of MBS or diluent. A two-tailed paired Student's $t$ test was used to determine the difference between sham-treated and MBStreated groups. The effects of MBS were expressed as a percentage of pretreatment control response at each frequency of stimulation. For agonist-induced concentration response curves, either acetylcholine-induced or substance P-induced responses were performed in the presence of either MBS or diluent. For responses to acetylcholine the effective concentration needed to cause $50 \%$ of the maximal contractile response $\left(\mathrm{EC}_{50}\right)$ was calculated from concentration-response curves. $\mathrm{EC}_{50}$ values are reported as geometric means and geometric standard error of the mean. The Mann-Whitney $U$ test was also used to analyse the differences. $p$ values of $<0.05$ were considered to be significant.

\section{Results}

MBS in concentrations ranging from $10^{-7} \mathrm{M}$ to $10^{-3} \mathrm{M}$ had no direct contractile effect on guinea pig trachea or bronchial preparations $(n=5-8)$. Removal of the airway epithelium had no effect on the direct contractile effects.
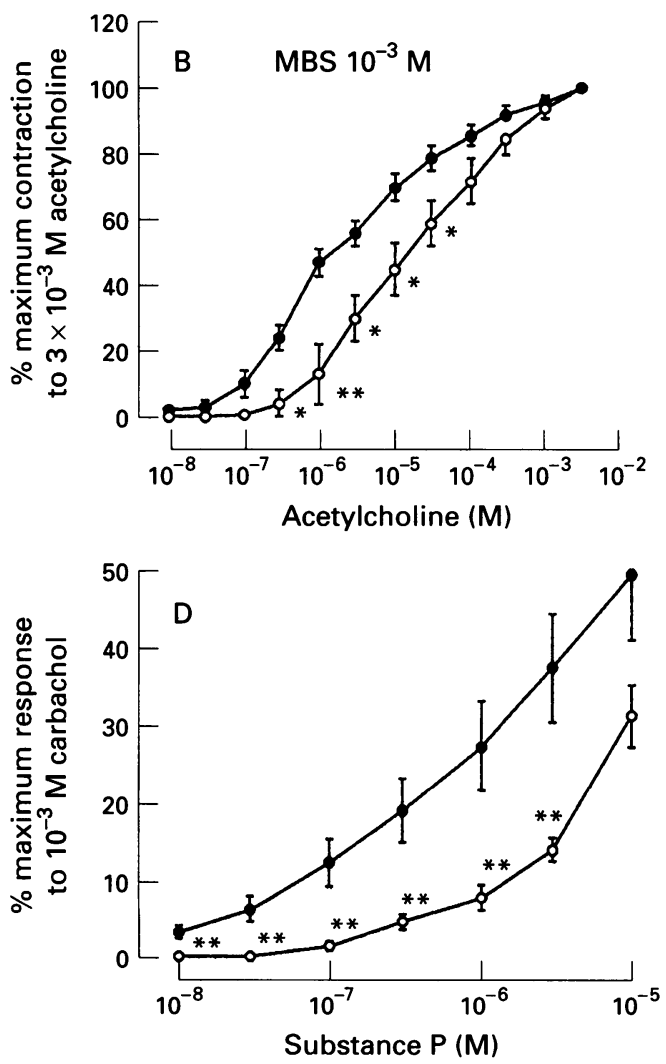

Figure 4 Effect of sodium metabisulphite $\left(M B S 10^{-6}\right.$ and $\left.10^{-3} \mathrm{M}\right)$ on contraction of $(A, B)$ guinea pig tracheal smooth muscle strips induced by exogenously applied acetylcholine, and $(C, D)$ guinea pig bronchial strips by substance $P$ in the presence of propranolol $\left(10^{-6} \mathrm{M}\right)$ and indomethacin $\left(10^{-5} \mathrm{M}\right)$. Data are shown as mean (SE) of 4-5 guinea pigs. Responses of tracheal smooth muscle are expressed as percentage of maximum contraction induced by acetylcholine $\left(3 \times 10^{-3} \mathrm{M}\right)$ or of bronchial strips by carbachol $\left(10^{-3} \mathrm{M}\right) .0=$ Sham-treated; $O=M B S$-treated. ${ }^{*} p<0.05$ ${ }^{* *} p<0.01$ compared with $M B S$-treated responses. 
EFFECT OF MBS ON RESPONSES TO ELECTRICAL FIELD STIMULATION

MBS $\left(10^{-7}-10^{-5} \mathrm{M}\right)$ had no effect on electrical field stimulation responses at frequency stimulation of $0.5-50 \mathrm{~Hz}$ in tracheal strips, apart from an augmentation at $0.5 \mathrm{~Hz}$. Figure 1 shows the effect of MBS at $10^{-6} \mathrm{M}$ in tracheal strips with an intact epithelium. By contrast, concentrations of MBS at $10^{-7}, 10^{-6}$, and $10^{-5}$ $M$ significantly enhanced non-adrenergic noncholinergic contractile responses in the guinea pig bronchial preparations (fig 2). The enhancement was maximal at a concentration of $10^{-6} \mathrm{M}(23.8(9 \cdot 6) \%)$. Although the enhancement found at $10^{-7} \mathrm{M}$ was significant when compared with responses after vehicle alone, this effect was small. The addition of diluent alone had no significant effect. This enhancement was unaffected by removal of airway epithelium in both tracheal and bronchial preparations.

At higher concentrations of MBS $\left(10^{-3}\right.$ and $\left.10^{-4} \mathrm{M}\right)$ there was a time-dependent attenuation of contractile responses induced by electrical field stimulation in both tracheal and bronchial preparations. Maximal inhibition was observed with $10^{-3} \mathrm{M}$ MBS within 15 minutes of incubation with a gradual loss of inhibition with successive stimulations (fig 3). Maximal recovery to baseline responses occurred by 75 minutes of incubation (fig 3). This was not affected by removal of the epithelium.

EFFECT OF MBS ON RESPONSES TO

RECEPTOR-MEDIATED STIMULI

MBS $\left(10^{-6} \mathrm{M}\right)$ had no effect on acetylcholineinduced isometric contractile responses in the tracheal strips either with or without epithelial denudation. However, at the higher concentration of $10^{-3} \mathrm{M}$ there was a significant increase in the $\mathrm{EC}_{50}$ from 2.36 (geometric standard error of mean 1.42$) \times 10^{-6} \mathrm{M}$ to $19.1(1.77) \times 10^{-6} \mathrm{M}(\mathrm{n}=5 ; \mathrm{p}<0.05)$, but maximal responses to acetylcholine were not inhibited. In addition, similar responses were observed with $\mathrm{MBS}$ at $10^{-3} \mathrm{M}$ on substance $\mathrm{P}$-induced contractile responses which were significantly inhibited at all concentrations for both tracheal and bronchial preparations; thus, at $10^{-6} \mathrm{M}$, substance $P$ induced a contractile response of $28(5 \cdot 0) \%$ of the maximal response compared with only $6 \cdot 2(2 \cdot 0) \%$ in the presence of MBS $\left(10^{-3} \mathrm{M}\right)$ ( $\mathrm{p}<0 \cdot 005$; fig 4$)$.

\section{Discussion}

We have shown that MBS does not have direct contractile responses on guinea pig airway smooth muscle. Although MBS did not augment the cholinergic component of the tracheal response to electrical field stimulation, it increased non-adrenergic non-cholinergic responses in bronchi at concentrations that did not affect contractile responses to substance P. Thus, MBS may augment the release of tachykinins from airway nerves induced by electrical field stimulation, while having no effect in the unstimulated airway preparation. At higher concentrations MBS inhibited contractile re- sponses to acetylcholine and substance $P$ in tracheal and bronchial strips, suggesting a generalised effect on airway contractile responses, possibly by an interaction of MBS with airway smooth muscle receptors. Our study shows that MBS has a complex modulatory role on airway smooth muscle depending on the level of the airway and the concentration of MBS.

We performed this study in order to elucidate the mechanisms by which inhaled MBS induces bronchoconstriction in patients with asthma, although non-asthmatic subjects usually do not respond. ${ }^{12}$ MBS has been shown to increase bronchial blood flow in the conscious sheep ${ }^{8}$ and to induce airway microvascular leakage in the guinea pig. ${ }^{6}$ MBS may therefore cause luminal airway narrowing through bronchial vasodilation and the induction of bronchial airway wall oedema. In view of the limited effect of anticholinergic agents in blocking MBS-induced bronchoconstriction in both asthmatic patients and guinea pigs, ${ }^{2-4}$ it has been proposed that MBS induces airway narrowing in vivo through indirect mechanisms such as activation of non-cholinergic nerves. We could not show a direct effect of MBS on isometric contractile responses in guinea pig trachea or bronchi, either in the presence or absence of an intact epithelium, which indicates that MBS does not have a direct contractile effect on airway smooth muscle. The absence of a cholinergic component in vitro, in contrast to the in vivo effects of cholinergic blockade, ${ }^{2-4}$ suggests that intact cholinergic pathways are necessary for showing such an effect.

Although MBS had no direct contractile effects, we found that it caused potentiation of contractile responses induced by electrical field stimulation in the presence of atropine with a maximal effect of the order of $24 \%$ at $10^{-6} \mathrm{M}$, a similar range to the potentiation induced by bradykinin. ${ }^{9}$ The effect of $\mathrm{MBS}$ at $10^{-7} \mathrm{M}$, however, although statistically significant, was small. Because there were no direct effects of MBS at these concentrations on isometric contractile responses induced by substance $P$, it is likely that MBS was enhancing the release of tachykinins from sensitisation of airway nerves. This effect has been previously reported for bradykinin. Miura and colleagues have shown that bradykinin at concentrations that had no direct contractile effects on guinea pig airways also potentiated non-adrenergic noncholinergic constrictor responses, presumably through an enhancement of tachykinin release. ${ }^{9}$ This effect was mediated through stimulation of bradykinin $\beta_{2}$ receptors. It is unlikely that the effects of MBS were mediated via this receptor because, in previous studies, we have shown that the bradykinin $\beta_{2}$ receptor antagonist was not effective in inhibiting MBSinduced airway effects in the guinea pig. ${ }^{10}$

There is evidence to suggest that sulphur dioxide, which is generated from MBS solutions, may activate airway nerves. Thus, $\mathrm{SO}_{2}$ delivered to the lower airways of anaesthetised dogs stimulates bronchial and pulmonary C fibres with reflex increases in tracheal smooth muscle tone. ${ }^{11}$ Our studies suggest that, in 
addition to inducing reflex effects, $\mathrm{SO}_{2}$ generated from MBS may enhance the stimulation of local airway $\mathrm{C}$ fibre. This may represent a mechanism by which local axon reflexes, which have been postulated in the airways, ${ }^{12}$ may be enhanced. An increase in the number of substance P-containing airway nerves has been reported in the airways of patients with asthma, ${ }^{13}$ an observation which may account for a greater propensity for bronchoconstriction to $\mathrm{MBS}$ in asthmatic than in non-asthmatic subjects. ${ }^{12}$

One mechanism by which sulphur dioxide and sulphites may induce bronchoconstriction in asthmatics is through their effect in increasing airway mucosal acidity. Sodium metabisulphite and sulphur dioxide convert to bisulphite ${ }^{14}$ and bisulphite, in turn, enters into equilibrium with the sulphite ions. ${ }^{15}$ These reactions are accompanied by the release of hydrogen ions, thereby acting as acids. Although the bronchoconstrictor effects of sodium sulphite, to which MBS is converted, are pHdependent with the greatest effects occurring at low $\mathrm{pH}$, acidity itself is unlikely to be the stimulus for bronchoconstriction. ${ }^{16}$ It is unlikely that the in vitro airway preparations were exposed to an acid solution because of the buffering capacity of the Kreb's solution. Addition of MBS to a maximum concentration of $10^{-3} \mathrm{M}$ to Kreb's solution did not alter its $\mathrm{pH}$. In addition, a solution of sulphuric acid with a similar $\mathrm{pH}$ to $\mathrm{MBS}$ at $10^{-3} \mathrm{M}$ did not induce airway smooth muscle contraction or augmentation of non-adrenergic, non-cholinergic responses.

Sodium sulphite is highly reactive with proteins ${ }^{17}$ and can bind to rat airways. ${ }^{18}$ Sulphite ions interact with disulphide bonds which can play a critical part in numerous cell membrane receptors. ${ }^{19}$ Sulphonation by sulphites of specific disulphide bonds in the neuromuscular junction has been shown to increase spontaneous acetylcholine release in frog pectoral muscle by acting through a presynaptic membrane protein. ${ }^{2021}$ In addition, sodium sulphite has been shown to increase transmitter release from the noradrenergic system in the mouse. ${ }^{22}$ Thus, MBS may increase the release of acetylcholine or tachykinins induced by electrical field stimulation through sulphonation of disulphide bonds prejunctionally.

At high concentrations of MBS the direct contractile effects of acetylcholine and substance $P$ were significantly inhibited with a rightward shift of the concentration-response curve without affecting the maximal response for the acetylcholine response. This suggests that MBS may be directly or indirectly acting as a competitive antagonist at the receptor sites of acetylcholine and substance $P$ in a reversible fashion. Contractile responses to electrical field stimulation were inhibited at high concentrations of MBS, which may result from an effect of the contractile neural mediator on airway smooth muscle rather than an effect on their release, although the latter mechanism cannot be completely excluded. These inhibitory effects were reversible with repeated successive stimulations. The mechanism for this reversible inhibitory effect is unclear. One potential mechanism may involve the further interaction of MBS at high concentrations with sulphydryl groups or disulphide bridges of various receptors on the smooth muscle membrane to alter receptor function or binding properties. ${ }^{23-25}$

This work was supported by a grant from the British Lung Foundation/BUPA.

1 Schwartz HJ, Chester EH. Bronchospastic responses to aerosolized metabisulfite in sensitive asthmatics: potential mechanisms and clinical implications. F Allergy Clin Immunol 1984;74:511-7.

2 Nichol GM, Nix A, Chung KF, Barnes PJ. Characterisation of bronchoconstrictor responses to sodium metabisulphite aerosol in atopic subjects with and without asthma. Thorax aerosol in atopic

3 Seale JP, Temple DM, Tennant CM. Bronchoconstriction by nebulised metabisulphite solutions $\left(\mathrm{SO}_{2}\right)$ and its modification by ipratropium bromide. Ann Allergy 1988;61: 209-13

4 Wright W, Zhang YG, Salome CM, Woolcock AJ. Effect of inhaled preservatives on asthmatic subjects. I. Sodium metabisulfite. Am Rev Respir Dis 1990;141:1400-4.

5 Sakamoto $T$, Tsukagoshi $\mathrm{H}$, Barnes PJ, Chung KF Involvement of tachykinin receptors $\left(\mathrm{NK}_{1}\right.$ and $\left.\mathrm{NK}_{2}\right)$ in sodium metabisulfite-induced airway effects. $A m R e v$ Respir Dis 1994;149:387-91.

6 Sakamoto T, Elwood W, Barnes PJ, Chung KF. Pharmacological modulation of inhaled sodium metabisulphite-induced airway microvascular leakage and bronchoconstriction in the guinea-pig. $B r \mathcal{F}$ Pharmacol bronchoconstriction

7 Elwood W, Sakamoto T, Barnes PJ, Chung KF. Allergeninduced airway hyperresponsiveness in the Brown-Norway rat: role of parasympathetic mechanisms. $\mathscr{f} \mathrm{Appl}$ Physio 1993;75:279-84.

8 Nichol GM, Parsons GH, Chung KF. Effect of sodium metabisulfite on bronchial blood flow in conscious sheep pharmacological modulation. Br 7 Pharmacol 1994;111: 918-22.

9 Miura M, Belvisi MG, Barnes PJ. Effect of bradykinin on airway neural responses in vitro. $\mathcal{F}$ Appl Physiol 1992;73: $1537-41$.

10 Sakamoto T, Sun J, Barnes PJ, Chung KF. Effect of $\beta_{2}$ bradykinin antagonist (HOE 140) against bradykinin and vagal stimulation-induced airway responses in the guinea vagal stimulation-induced airway respons
pig. Eur $₹$ Pharmacol 1994;251:137-42.

11 Roberts AM, Hahn HL, Schultz HD, Nadel JA, Coleridge $\mathrm{HM}$, Coleridge JCG. Afferent vagal C fibres are responsible for the reflex airway constriction and secretion evoked by pulmonary administration of $\mathrm{SO}_{2}$ in dogs. Physiologist 1982;25:226.

12 Barnes PJ. Asthma as an axon reflex. Lancet 1986;i:242-5.

3 Ollerenshaw SL, Jarvis D, Sullivan CE, Woolcock AJ. Substance $P$ immunoreactive nerves in airways from asthmatics and nonoretive nerves in 7 1991;4:673-82.

matics and non-asthmatics. Eur Respir $\mathcal{F}_{1} 1991,4: 673-82$. uss A, Eckert C. Equilibria and ion activities in aqueous sulfur dioxide solutions. F Physiol Chem 1977;81:2268-70

15 Hayon E, Treinin A, Wilf J. Electronic spectra, photochemistry and auto-oxidation mechanism of the sulfitebisulfite-pyrosulfite systems. The $\mathrm{SO}_{2}^{-}, \mathrm{SO}_{3}^{-}, \mathrm{SO}_{4}^{-}$and $\mathrm{SO}_{5}{ }^{-}$radicals. $\mathcal{F} \mathrm{Am}$ Chem Soc 1972;94:47-57.

16 Fine JM, Gordon T, Sheppard D. The roles of $\mathrm{pH}$ and ionic species in sulfur dioxide- and sulfite-induced bronchoconstriction. Am Rev Respir Dis 1987;136:1122-6.

17 Petering DH, Shih NT. Biochemistry of bisulfite-sulfur dioxide. Environ Res 1975;9:55-65.

18 Dahl AR, Furst GM, Hahn FF. Binding of sulfite-introduced ${ }^{35} S$ to the pleura and walls of conducting airways in rat lungs. Toxicol Lett 1981;8:295-8.

19 Strauss WL. Sulfhydroxyl groups and disulfide bonds: modifications of amino acid residues in studies of receptor structure and function. In: Ventner JC, Harrison LC, eds. Membranes, detergents and receptor solubilisation. New York: Membranes, detergents and nece

20 Steinacker A. Sulphonation of cholinergic receptor disulphide bond increases response to ACh. Nature 1979; 278:358-60.

21 Steinacker A. Presynaptic effects of sodium bisulfite at the frog neuromuscular junction. $\mathcal{F}$ Neurosci Res 1982;7 313-9.

22 Dembiec D, Cohen G. Effect of carbonyl-binding agents and oxidative phosphorylation uncouplers on the release of $\left({ }^{3} \mathrm{H}\right)$ norepinephrine from mouse heart. Biochem Pharmacol 1976;25:1369-76.

23 Aronstam RS, Abood LG, Hoss W. Influence of sulfhydryl reagents and heavy metals on the functioned state of the muscarinic acetylcholine receptor in rat brain Pharmacol 1978;14:575-86.

24 Asano $M$, Hidaka $H$. Alterations in pharmacological receptor activities of rabbit arteries by sulphydryl reagents. ceptor activities of rabbit arteries
fap $\mathcal{f}$ Pharmacol $1983 ; 33: 227-40$.

25 Biassoni R, Vaccari A. Selective effects of thiol reagents on the binding sites for imipramine and neurotransmitter amines in the rat brain. Br $\mathcal{F}$ Pharmacol 1985;85:447-56. 